\title{
Efeitos da Integração Nacional e Difusão de Conhecimento sobre a Trajetória de Crescimento Econômico
}

\author{
Emerson Marinho \\ Flávio Ataliba
}

Edinaldo Tebaldi

\author{
Professor do Curso de Pós-Graduação em Economia - CAEN \\ e do Departamento de Economia da UFC \\ Professor do Curso de Pós-Graduação em Economia - CAEN \\ e do Departamento de Economia da UFC
}

Doutorando pela University of New Hampshire

\section{RESUMO}

Este artigo discute os efeitos da integração nacional à luz da teoria do crescimento endógeno. Neste sentido, avalia-se como diferentes hipóteses sobre a difusão de conhecimento e qualificação de mão-de-obra afetam as trajetórias do produto, do capital e do consumo. Mostra-se que na ausência de difusão de conhecimento a integração entre regiões desiguais faz com que aquela mais atrasada se especialize na produção de bens manufaturados, enquanto a outra permanece diversificada na produção de manufaturados e de novos projetos, governando a trajetória de crescimento de ambas as regiões. Por outro lado, se a difusão de conhecimento ocorre, ambas as regiões continuam engajadas na produção de bens manufaturados e de novas tecnologias. Além do mais, a integração nacional tem efeitos positivos sobre a trajetória de crescimento independentemente da difusão de conhecimento.

\section{PALAVRAS-CHAVE}

crescimento econômico, integração nacional, difusão de conhecimento

\section{ABSTRACT}

This paper deals with the overall effects on national integration based upon the endogenous growth theory. The core assignment is to evaluate how different hypotheses on the knowledge diffusion and qualification of labor among integrated regions affect the growth path of product, capital and consumption. It is demonstrated that in the absence of knowledge diffusion, the least developed region tends to become specialized in manufacturing, while the leader region keeps its manufacturing diversification and dictates the growth path of all regions. On the other hand, if the knowledge diffusion takes place, all

regions maintain the manufacturing diversification process and creation of new technologies. Yet, it is also verified that a nationwide integration affects positively the economic growth path, regardless the knowledge diffusion.

KEY WORDS economic growth, national integration, knowledge diffusion

JEL Classification

OII 


\section{INTRODUÇÃO}

A literatura que trata da problemática regional tem como elemento central de análise explicar a divergência na trajetória de crescimento econômico entre regiões de um país onde coexistam áreas relativamente atrasadas e outras desenvolvidas. Um dos diagnósticos principais para tal fenômeno recaía sobre a ausência de integração espacial da economia nacional. ${ }^{1}$

Diante dessa suposição, surgem propostas de intervenção governamental visando promover a integração espacial nacional e, com isso, alavancar o processo de crescimento das regiôes, de modo a reduzir as desigualdades. A argumentação é que a integração espacial nacional pode ampliar o fluxo de bens, capital e força de trabalho, e com isso aumentar a eficiência do setor produtivo, promovendo uma maior especialização, afetando a localização da atividade industrial de tal forma que no longo prazo se possa atingir uma trajetória comum de crescimento do produto nas áreas integradas.

Discussões no âmbito da integração regional também geraram conhecimentos aplicáveis à integração nacional. ${ }^{2}$ Nessa literatura as discussões passaram a ficar polarizadas entre os ganhos estáticos e dinâmicos da integração, sendo que a teoria tradicional do comércio internacional enfoca os ganhos estáticos, enquanto modelos modernos, baseados na teoria do crescimento endógeno, tratam dos ganhos dinâmicos.

Ambas as correntes consideram que a integração imperfeita pode gerar distorções e com isso haver ganhadores e perdedores ao longo do processo, como em Krugman (1991), Vernables (1996), Frenkel e Trauth (1998) e Baldwin e Forsted (1999), dentre outros. Tanto no campo da integração

1 Para uma discussão acerca dessa questão, veja FRIEDMAN (1977) e ABLAS (1985).

2 Segundo MACHLUP (1976), apud ROLIM (1994), o uso do termo Integração para indicar a combinação de economias separadas é relativamente recente, sendo que este termo pode gerar dúvidas na sua interpretação se não estiver bem definido. Segundo o autor, uma simples adjetivação pode resolver tais problemas de interpretação. Isso posto, neste trabalho se considerará as definições sugeridas por MACHLUP (1976), onde se utiliza: integração nacional (intranacional), integração regional (multinacional, bloco de países) e integração mundial (global, universal). Da mesma forma, pode-se distinguir a integração setorial (referente a um os mais setores dos países ou regiões envolvidas) da integração econômica geral (total da economia). 
nacional quanto na regional, nota-se que a preocupação com a questão comercial e financeira é mais acentuada se comparada às discussóes relativas ao fluxo de conhecimento e capital humano gerado.

As idéias prevalecentes no Brasil nos últimos 40 anos e que influenciaram as ações governamentais até o presente sugeriram que o desequilíbrio regional no País seria resolvido por meio de medidas que privilegiassem a integração nacional especialmente via aumento do fluxo de capital financeiro para as regióes mais pobres. Nesse contexto, a criação da Sudene e da Sudam e dos programas de financiamento ao capital, Finor e Finam, é uma amostra de como é entendido, no Brasil, o problema do desequilíbrio regional.

A despeito da implementação dessas medidas, diversos trabalhos empíricos têm constatado que ainda persiste uma forte desigualdade socioeconômica entre as regióes brasileiras, especialmente quando se compara o Norte e Nordeste ao Centro-Sul do País. ${ }^{3}$ Desta forma, é salutar que se pense, em outras bases, o problema regional brasileiro e as formas de integração entre as regióes.

A teoria do crescimento endógeno tem chamado atenção para o fato de que o desenvolvimento científico-tecnológico e o incremento dos fluxos de informação podem ser considerados elementos centrais para o entendimento da dinâmica do crescimento das economias. Rivera-Batiz e Romer (1990) e Frenkel e Trauth (1998) mostram, por exemplo, que a integração econômica afeta o fluxo de conhecimento e de capital humano e, conseqüentemente, a trajetória de crescimento das regiões ou países que tenham se integrado.

Neste contexto, esse artigo procura contribuir para o debate sobre desequilíbrio regional focando o processo de integração econômica entre regiões de um mesmo país levando-se em conta diferentes hipóteses sobre

3 O trabalho de LAVINAS, GARCIA \& AMARAL (1996) apresenta importantes indicadores do atual nível de desigualdade regional no Brasil. 
a dotação inicial de capital humano, difusão de conhecimento e qualificação de mão-de-obra. Com base nos trabalhos citados acima, verifica-se como as trajetórias do produto, do estoque de capital e do consumo entre regiões de um mesmo país se comportam quando se alteram algumas hipóteses iniciais desses modelos. O relaxamento dessas hipóteses torna-se importante, pois permite avaliar como diferentes políticas públicas podem alterar as trajetórias de crescimento das regiões e seus processos de integração.

O trabalho está organizado da seguinte forma: além dessa introdução, na próxima seção é apresentada uma breve revisão da literatura sobre integração econômica e difusão de tecnologia. Na seção 2 é construído o modelo teórico e derivadas as condições de equilíbrio da economia. Na seção 3 discute-se como a economia se comporta diante da hipótese de integração imperfeita no setor tecnológico, ou seja, avaliam-se os efeitos da integração sob a hipótese de ausência de difusão de conhecimento. Na quarta seção, os efeitos da integração são analisados quando existe a difusão de conhecimento entre as regiões. Na última seção os resultados do trabalho são sumariados.

\section{REVISÃO DA LITERATURA}

Este trabalho está relacionado à literatura que trata da integração econômica e crescimento, e tem como trabalhos seminais os de Krugman (1987) e Rivera-Batiz-Romer (1990). Esses estudos analisam os efeitos da integração na trajetória de crescimento econômico, sendo que Krugman considera países com diferentes estágios de desenvolvimento, enquanto Rivera-Batiz e Romer consideram países similares.

O trabalho de Krugman (1987) mostra que a integração conduz à especialização e que não ocorre a convergência da renda. O trabalho destaca que a integração torna os países completamente especializados nos setores nos quais têm vantagens comparativas. Assim, o país que tiver um setor tecnológico relativamente pouco desenvolvido terá desvantagem comparativa e deverá cessar a produção de novos projetos especializando-se na produção de bens nos quais tenha vantagens comparativas. 
O artigo de Rivera-Batiz e Romer (1990) se apresenta como um contraponto aos resultados dos modelos neoclássicos de crescimento existentes até então, sugerindo, peremptoriamente, que os efeitos da integração são pequenos. Segundo os autores, os modelos de crescimento endógeno mostram que os resultados são muito mais importantes ao incorporar elementos desprezados nas demais formulações. As principais inovações deste trabalho são: i) a incorporação do fluxo de idéias entre regiões integradas como elemento central para explicar os efeitos da integração e; ii) o estabelecimento da premissa de que o mercado de bens intermediários é monopolista. ${ }^{4}$

As principais conclusões de Rivera-Batiz e Romer são que a integração pode aumentar a taxa de crescimento de longo prazo e fortalecer a exploração dos retornos crescentes de escala em pesquisas, com o conseqüente desenvolvimento do setor de P\&D. Dessa forma, os benefícios da integração sobre o crescimento são gerados pela alocação mais eficiente da produção e também pela transmissão de conhecimento.

Frenkel e Trauth (1998) estendem as análises de Rivera-Batiz e Romer (1990) ao avaliar a integração entre países que têm estruturas econômicas diferenciadas, como taxa de preferência, produtividade e dotação de capital humano. Nesse trabalho é demonstrado que os efeitos da integração econômica sobre o crescimento dependem de como o conhecimento flui entre as nações e que na ausência da difusão tecnológica deve ocorrer a especialização setorial.

O trabalho de Giannetti (1999) mostra que o conhecimento de spillovers responsável pela aceleração da acumulação de experiência no setor de $\mathrm{P} \& \mathrm{D}$ - e o alargamento dos mercados constituem-se nos principais elementos positivos da integração. Segundo a autora, regiões com diferentes estruturas industriais não se beneficiam da mesma maneira na transmissão de conhecimento, sendo que a integração econômica exacerba as disparidades

4 Nas próximas seções do trabalho se discutirá como essa hipótese é incorporada nos modelos de crescimento endógeno. 
entre regiões de um país e acelera o crescimento e a convergência entre países. Além disso, regiões com setor de P\&D de alta tecnologia crescem mais rápido e convergem independentemente das diferenças nos níveis de produtividade iniciais.

Convém lembrar que esse estudo também identifica alguns fatos estilizados sobre a evolução da integração regional na Europa durante os últimos anos e mostra alguns resultados da integração entre países caracterizados por fortes disparidades regionais, originadas de uma baixa produtividade no setor de P\&D. É destacado que as diferenças de renda entre os países caiu, e que isto se deve ao avanço tecnológico, resultado da difusão de conhecimento.

Os modelos de crescimento endógeno, citados acima, tipicamente assumem que o conhecimento é completamente difundido dentro da economia de cada país, enquanto, implícita ou explicitamente, admitem que a difusão entre diferentes economias não acontece ou é imperfeita, no sentido de a difusão acontecer com significativa defasagem e de forma incompleta.

De fato, a hipótese de difusão dentro das fronteiras de cada país é forte e pode não retratar a realidade, pois a difusão nacional do conhecimento depende de um conjunto de fatores intrínsecos a cada região que podem inexistir, ou de serem insuficientes ou mesmo inapropriados para absorverem determinadas informações, tais como: a) meios de comunicação; b) instituições capazes de armazenar, processar e difundir as informações; c) capital humano; d) capital físico que possa ser combinado com o conhecimento para gerar novos produtos (bens de consumo capital, etc.) etc. Em suma, tais fatores podem afetar o deslocamento do conhecimento de maneira tal que a difusão ocorra apenas em uma região geograficamente localizada.

Fazendo um paralelo em matéria de economia regional e urbana, a aglomeração e a dispersão da atividade econômica são explicadas pelos custos de transporte, externalidades e retornos crescentes de escala. Quanto aos fatores geográficos que afetam a difusão de conhecimento, uma explicação similar é também mostrada na literatura, de forma que as externalidades 
tecnológicas de localização são uma explicação para a aglomeração e a dispersão. (KELLER, 2000). Nessa mesma linha, o trabalho de Jaffe e Trajtenberg (1996) discute o impacto da difusão de conhecimento na localização das patentes, porém não aborda os impactos da difusão em termos de produtividade ou do produto.

Isto posto, o objetivo desta rápida revisão de literatura foi mostrar que existem vários trabalhos que estudam os efeitos da integração entre países, porém muito pouco se discute a respeito da integração nacional. Por sua vez, a integração exige basicamente a integração comercial, financeira e tecnológica entre as regiões de um país. Naturalmente, cada um desses elementos é influenciado e determinado por um conjunto de forças e fatores particulares.

Portanto, a existência de muitos fatores e forças que operam em diferentes sentidos torna difícil que um modelo consiga explicar ao mesmo tempo os resultados globais da integração. Não obstante, faz-se necessário restringir a atenção a um determinado elemento da integração e procurar entender os fatores que o afetam e suas conseqüências sobre a trajetória da economia das regiões e do país. Nesse marco, este trabalho discutirá apenas os efeitos da integração entre regiões de um país, avaliando como diferentes hipóteses sobre a difusão de conhecimento e a qualificação de mão-de-obra afetam as trajetórias do produto, do consumo e do capital.

\section{ESPECIFICAÇÃO DO MODELO TEÓRICO}

O modelo apresentado a seguir é baseado em Rivera-Batiz e Romer (1990) e Frenkel e Trauth (1998). No entanto, neste artigo, relaxam-se algumas hipóteses desses trabalhos, acrescentando-se as hipóteses de crescimento populacional e de capital humano ao longo do tempo, e a possibilidade ou não de difusão de conhecimento entre regiões de um país e economias similares. 
Supõe-se que o país é composto por duas regiões que ainda não estão integradas comercial e financeiramente, sendo que as variáveis sem asterisco representam a região 1 e com asterisco a região 2 . A economia de cada região é dividida em dois setores: o setor manufatureiro - que produz bens de consumo e de capital -, e o setor de P\&D - que produz novos projetos para inovar os bens de capital. O estoque de conhecimento da economia aumenta como um subproduto de cada invenção, e cada nova invenção adicionada ao estoque de conhecimento facilita pesquisas futuras. Além disso, os pesquisadores não produzem bens intermediários e obrigatoriamente vendem os direitos de propriedade dos novos projetos para os produtores de bens intermediários. Por sua vez, nenhum produtor de bens intermediários pode produzir sem autorização do inventor, isto é, sem comprar uma patente.

Uma crucial característica deste modelo é que os pesquisadores podem despender tempo estudando um novo projeto (invenção), podendo, com isso, acumular conhecimento que pode ser utilizado no desenvolvimento de novos projetos. Em outras palavras, o conhecimento é um bem passível de ser parcialmente excluído, isto é, o inventor de um bem não tem a habilidade de impedir que outros pesquisadores aprendam a tecnologia (conhecimento) incluída em um novo projeto. ${ }^{5}$ A principal implicação dessa hipótese é que o conhecimento gerado por meio da invenção de novos projetos pode ser completamente aprendido por todos os pesquisadores, o que significa que novas invenções aumentam o estoque de conhecimento de uma região.

Ambos os aspectos da inovação mencionados acima fazem a produtividade da economia crescer, isto porque, de um lado, novos projetos aumentam a quantidade e a diversidade do estoque de capital e, portanto, a produtividade do setor manufatureiro e, por outro, o setor de P\&D incorpora os novos projetos e aumenta seu estoque de conhecimento, conduzindo a pesquisas mais sofisticadas com um dado fator de insumo.

5 Uma discussão mais detalhada deste tópico pode ser encontrada em ROMER (1990, p. 84). 
Assume-se também que a região 1 tem um estoque de conhecimento maior que o da região 2, indicando que as regióes têm níveis de crescimento econômico diferenciados. A população total de ambas as regióes é igual e cresce à mesma taxa " $n$ ", sendo que a região 1 qualifica uma fração constante $\mu \in[0,1]$ da população que está surgindo, tal que:

$$
\begin{aligned}
& \dot{\mathrm{H}}=\mu \dot{\mathrm{P}} \\
& \dot{\mathrm{L}}=(1-\mu) \dot{\mathrm{P}}
\end{aligned}
$$

onde $\dot{\mathrm{H}}$ é o crescimento da mão-de-obra qualificada $(\mathrm{H}), \dot{\mathrm{L}}$ é o crescimento da mão-de-obra não qualificada (L) e $\dot{\mathrm{P}}$ é o crescimento da população. A alocação do Capital Humano $\left(\mathrm{H}^{*}\right)$ entre os setores de P\&D e manufaturados é endógena e será discutida na seção 2.3.

Por sua vez, a região 2 qualifica uma fração constante $\lambda \in[0,1]$ da população que está surgindo, tal que:

$$
\begin{aligned}
& \dot{\mathrm{H}}^{*}=\lambda \dot{\mathrm{P}^{*}} \\
& \dot{\mathrm{L}^{*}}=(1-\lambda) \dot{\mathrm{P}^{*}}
\end{aligned}
$$

onde $\dot{\mathrm{H}}^{*}$ é o crescimento da mão-de-obra qualificada $\left(\mathrm{H}^{*}\right), \dot{\mathrm{L}}^{*}$ é o crescimento da mão-de-obra não qualificada $\left(\mathrm{L}^{*}\right)$ e $\dot{\mathrm{P}}^{*}$ é o crescimento da população.

\subsection{Lado da Oferta}

A partir deste ponto utilizar-se-á a região 1 como referência para as análises, subentendendo que as definições apresentadas são válidas para ambas 
as regiões. Vale ressaltar também que, por simplicidade de notação, será omitido o argumento das variáveis que dependem do tempo. Assim sendo, o setor manufatureiro produz $(\mathrm{Y})$ utilizando trabalho não qualificado $(\mathrm{L})$, capital humano (HY) e o conjunto de bens de capital produzidos na própria região $(\mathrm{x})$ e os bens de capital importados da outra região $(\mathrm{m})$. Os bens de consumo e de capital são produzidos com a mesma tecnologia e, por simplicidade, assume-se que a mesma quantidade de recursos é utilizada para produzir uma unidade de bem de consumo ou, alternativamente, de capital, ou seja, a taxa marginal de substituição entre bens de consumo e de capital é unitária.

A equação (1) caracteriza o estoque de capital (K) como a soma de todos os bens de capital produzidos na região 1 e importados da região 2 . Os índices i e j representam os diferentes bens de capital já inventados, sendo que $i \in[0, A]$ e $j \in\left[0, A^{*}\right]$. A fim de evitar problemas de solução das equações, i e j são definidos de forma contínua. Isso posto, e em conseqüência das definiçóes anteriores, tem-se o seguinte conjunto de equações que descrevem uma determinada economia.

O estoque de capital da economia é dado por:

$$
K=\int_{0}^{A} x(i) d i+\int_{0}^{A^{*}} m(j) d j
$$

A função de produção utilizada segue a formulação de Rivera-Batiz e Romer (1990), a qual descreve o produto por: $\mathrm{Y}=\mathrm{F}(\mathrm{HY}, \mathrm{L}, \mathrm{x}, \mathrm{m})$. Assim, as funções de produção das regiões 1 e 2 são definidas, respectivamente, por:

$$
\begin{gathered}
Y=H_{Y}^{\alpha} L^{\beta}\left[\int_{0}^{A} x(i)^{\gamma} d i+\int_{0}^{A *} m(j)^{\gamma} d j\right] \\
Y^{*}=H_{Y}^{* \alpha} L^{* \beta}\left[\int_{0}^{A *} x *(i)^{\gamma} d i+\int_{0}^{A} m^{*}(j)^{\gamma} d j\right]
\end{gathered}
$$


Por hipótese, as elasticidades do capital humano, do trabalho não qualificado e dos bens de capital, em relação ao produto, são iguais para ambas as regiôes. ${ }^{6}$ Ao se analisar a economia em um determinado momento do tempo, digamos $t_{k}$, os estoques de conhecimento $A$ e $A^{*}$ estarão fixos, sendo então assumido que as funções de produção descritas pelas equações (2) e (3) apresentam retornos constantes de escala, ou seja: $\alpha+\beta+\gamma=1$. Por sua vez, novos projetos aumentam o conjunto de bens de capital e, conseqüentemente, a fronteira de possibilidade de produção.

O setor de P\&D utiliza somente capital humano para produzir novos projetos, sendo a sua função de produção definida pela equação (4), para a região 1 , e pela equação (5), para a região 2.

$$
\begin{gathered}
\dot{\mathrm{A}}=\mathrm{A}_{\mathrm{A}} \delta \mathrm{H}_{\mathrm{A}} \\
\dot{\mathrm{A}} *=\mathrm{A}_{\mathrm{A}}^{*} \delta^{*} \mathrm{H}_{\mathrm{A}}^{*}
\end{gathered}
$$

onde: $\dot{A}=$ Crescimento de novos projetos (conhecimento);

$\mathrm{A}_{\mathrm{A}}=$ Estoque de conhecimento disponível para pesquisas;

$\mathrm{H}_{\mathrm{A}}=$ Capital Humano alocado no setor de P\&D;

$\delta=$ parâmetro produtividade, sendo $\delta>0$.

6 A princípio poder-se-ia supor que a elasticidade dos bens de capital produzidos na própria região (x) deveria ser diferente da elasticidade dos bens de capital importados (m). Entretanto, os bens de capital importados são somados ao de bens de capital produzidos internamente, de maneira que o total de bens capital que podem ser usados na produção aumenta. Assim, parece plausível assumir que a elasticidade do capital é a mesma, independente de sua origem. É importante ressaltar que a hipótese de simetria das funções de produção é uma hipótese relativamente forte quando se analisa a economia de cada regiấo em autarcia. Contudo, o setor de manufaturados não é o setor dinâmico dessa hipotética economia e os objetivos do trabalho estão centrados nos problemas vinculados ao setor de P\&D, o qual é o motor da economia. Portanto, eventuais "prejuízos" devidos ao uso dessa hipótese são minimizados. 
O total de capital humano de cada região é a soma do capital humano alocado na manufatura e no setor de P\&D. Em particular para a região 1,0 capital humano ${ }^{7}$ é expresso pela seguinte equação:

$$
\mathrm{H}=\mathrm{H}_{\mathrm{Y}}+\mathrm{H}_{\mathrm{A}}
$$

Conforme as equações descritas acima, o capital humano $(\mathrm{H})$ é utilizado no setor de manufatura e em $\mathrm{P} \& \mathrm{D}$, enquanto o trabalho não qualificado (L) é utilizado somente na manufatura. Observe nas equações acima que a política de qualificação de capital humano afeta o crescimento de novos projetos da economia. Para a região 1, por exemplo, tem-se: ${ }^{8}$

$$
\mathrm{H}_{\mathrm{A}}=\mathrm{H}-\mathrm{H}_{\mathrm{Y}}=\mu \mathrm{P}-\mathrm{H}_{\mathrm{Y}}
$$

Portanto, como HA é uma função crescente de $\mu$, quanto maior a fração da população que está sendo qualificada $(\mu)$, maior o estoque de capital humano da economia e, por conseqüência, maior a taxa de crescimento de novos projetos.

\subsection{Estrutura de Mercado}

O modelo trabalha com a hipótese de que dentro do conjunto de bens de capital representado por $x(i), m(j), x(i)^{*} e \mathrm{~m}(j)^{*}$ as condições de oferta e demanda são as mesmas em cada região. Como conseqüência, em equilíbrio os preços e quantidades de cada tipo de bem de capital são iguais, ${ }^{9} \mathrm{de}$ maneira que $x(i)=x, m(j)=m, x(i)^{*}=x^{*} e m(j)^{*}=m^{*}$.

7 Entende-se que o capital humano consiste das habilidades, destreza e conhecimento de um trabalhador em particular, sendo que o capital humano, como os demais bens econômicos convencionais, é rival e excludente, ou seja, o seu uso em uma atividade exclui o seu uso em outra. (ROMER, 1996). Neste trabalho, considera-se tal conceito extrapolando que o capital humano é altamente qualificado.

8 Usando $\dot{\mathrm{H}}=\mu \dot{\mathrm{P}}$ e assumindo que $\mathrm{H}(0)=\mu \mathrm{P}(0)$.

9 Para uma discussão mais detalhada, ver ROMER (1990, p. S81). 
Admite-se que para produzir bens de capital o produtor do setor de bens intermediários precisa comprar os direitos de patente de um empresário de P\&D, sendo que os custos de sua aquisição independem do número de bens de capital que serão produzidos. $\mathrm{O}$ produtor tem o incentivo para comprar os direitos de patente à medida que se torna monopolista num tipo distinto de bem de capital.

Considerando a hipótese de inexistência de barreiras à entrada na produção de bens intermediários, o que gera competição monopolista neste setor, dois importantes aspectos da condição acima merecem ser salientados: o primeiro é que o poder de monopólio do produtor de bens intermediários deriva da existência de custos fixos de produção, isto é, uma vez que se compra os direitos de uma patente o produtor pode produzir o quanto desejar sem incorrer em custos crescentes. O segundo é que o crescimento da economia e o conseqüente aumento da demanda de bens intermediários não implica custos crescentes, que, por sua vez, aumenta a produtividade do trabalho e do capital, sustentando o crescimento. (AGHION \& HOWITT, 1998 e ROMER, 1990).

Seguindo Romer (1990), o problema de otimização do monopolista é resolvido assumindo que não existe depreciação, de tal forma que o custo marginal de oportunidade do monopolista é simplesmente a taxa de juro, $r$. Além disso, a curva de demanda dos manufatureiros é conhecida, pois os manufatureiros estão dispostos a pagar um preço igual ao produto marginal do bem de capital que estão comprando. Para obter o produto marginal de x e m basta derivar a equação (2) em relação a x e m, obtendo-se ${ }^{10}$

$$
\frac{\partial Y}{\partial x}=\gamma H_{Y}^{\alpha} L^{\beta} x^{\gamma-1}
$$

10 Observe que ao se analisar a economia em um determinado momento do tempo, os valores de A e $\mathrm{A}^{*}$ estarão fixos, tal que as derivadas de $\mathrm{Y}$ em relação a $\mathrm{x}$ e $\mathrm{m}$ não são afetadas pelo valor de $\mathrm{A}$ e $A^{*}$. 


$$
\frac{\partial Y}{\partial m}=\gamma H_{Y}^{\alpha} L^{\beta} m^{\gamma-1}
$$

Considerando que o preço pago pelo monopolista pela patente é um custo fixo e não afeta a função de maximização lucro, e desde que a renda oriunda da venda dos bens de capital é dada por $\left(\mathrm{p}_{\mathrm{x}} \mathrm{x}+\mathrm{p}_{\mathrm{m}} \mathrm{m}^{*}\right)$ e o custo de oportunidade do capital dado por $r\left(x+m^{*}\right)$, a função lucro do monopolista pode ser escrita como segue:

$$
\mathrm{p}=\left(\mathrm{p}_{\mathrm{x}} \mathrm{x}+\mathrm{p}_{\mathrm{m}} \mathrm{m}^{*}\right)-\mathrm{r}\left(\mathrm{x}+\mathrm{m}^{*}\right)
$$

Em Mas-Colell (1995) e Varian (1992) é demonstrado que é ótimo para o monopolista escolher um "markup" constante sobre seu custo marginal, tal que o monopolista deve operar com um nível de preços dado por:

$$
p=\frac{r}{1+1 / \varepsilon}
$$

onde $\varepsilon$ é a elasticidade preço da demanda.

Desde que os manufatureiros estão dispostos a pagar um preço igual ao produto marginal do bem de capital que estão comprando, pode-se resolver as equações (7) e (8) para x e m, e então calcular suas derivadas em relação a seus preços, gerando a elasticidade-preço da demanda pelos bens de capital. Assim, verifica-se que as elasticidades de x e m são iguais e dadas por:

$$
\varepsilon_{\mathrm{x}}=\varepsilon_{\mathrm{m}}=\frac{1}{\gamma-1}
$$

Portanto, o nível de preços que maximiza o lucro do monopolista em bens de capital é: 


$$
\mathrm{p}=\mathrm{p}_{\mathrm{x}}=\mathrm{p}_{\mathrm{m}}=\frac{\mathrm{r}}{1+1 / \varepsilon_{\mathrm{x}}}=\frac{\mathrm{r}}{\gamma}
$$

Por isso, é ótimo para o monopolista escolher um markup constante sobre seu custo marginal, sendo que a sua magnitude depende da elasticidadepreço da demanda dos bens de capital. Em outras palavras, quanto maior a elasticidade-preço da demanda, mais o preço se aproximará do custo de oportunidade e, conseqüentemente, do preço de mercado competitivo. Substituindo o valor de p na função lucro, $\pi$, têm-se: ${ }^{11}$

$$
\pi=\frac{1-\gamma}{\gamma}(\mathrm{x}+\mathrm{m} *) \mathrm{r}
$$

Usando (7) e (8) juntamente com o fato que $\mathrm{p}_{\mathrm{x}}=\mathrm{p}_{\mathrm{m}}=(\mathrm{r} / \gamma)$ e $1-\gamma=\alpha+\beta$, obtém-se a função de demanda por $\mathrm{x}$ e $\mathrm{m}$ expressa em termos de capital humano, trabalho não qualificado e da taxa de juro, como segue:

$$
x=m=\gamma^{\frac{2}{(\alpha+\beta)}} H_{Y} \frac{\alpha}{(\alpha+\beta)} \frac{\beta}{L^{(\alpha+\beta)}} r^{\frac{-1}{(\alpha+\beta)}}
$$

Utilizando procedimento similar ao usado para derivar a equação (10), juntamente com a equação (3), obtém-se:

$$
x^{*}=m^{*}=\gamma^{\frac{2}{(\alpha+\beta)}} H_{Y}^{* \frac{\alpha}{(\alpha+\beta)}} L^{* \frac{\beta}{(\alpha+\beta)}} r^{\frac{-1}{(\alpha+\beta)}}
$$

11 A derivação da função lucro $(\pi)$ e do preço da patente $\left(\mathrm{P}_{\mathrm{A}}\right)$, apresentadas a seguir, não explicita que $\rho$ e p variam no tempo, como, por exemplo, em ROMER (1990, p. 587). Todavia, essas variáveis são endogenamente determinadas e, obviamente, qualquer mudança que venha a ocorrer na economia ao longo do tempo irá afetá-las. Em outras palavras, $r$ e $\pi$ variam ao longo do tempo. 
As equações (10) e (11) mostram que as demandas pelos bens de capital, produzidos nas regióes 1 e 2, são iguais. Assim, em equilíbrio, a produção manufatureira utilizará bens de capital da própria região e da outra na mesma proporção.

Quanto ao preço da patente $\mathrm{P}_{\mathrm{A}}$, este é determinado em um mercado oligopolista, onde os demandantes são os potenciais produtores de manufaturas e os ofertantes os produtores de novos projetos. $\mathrm{O}$ manufatureiro está disposto a comprar um projeto desde que seu preço se iguale ao valor presente de todos os lucros futuros oriundos dessa nova tecnologia. Assim:

$$
\mathrm{P}_{\mathrm{A}}=\int_{0}^{\infty} \mathrm{e}^{-\mathrm{rt}} \pi \mathrm{dt}=\frac{\pi}{\mathrm{r}}
$$

Substituindo o valor de $\pi$, obtido da equação (9), chega-se à:

$$
P_{A}=\left(\frac{\alpha+\beta}{\gamma}\right)(x+m *)
$$

Em equilíbrio, o monopolista utiliza todo o lucro da sua produção e venda dos bens de capital para pagar a patente. Por sua vez, será demonstrado que o preço da patente determina a remuneração paga ao capital humano no setor de P\&D, de tal forma que, em equilíbrio, o lucro neste setor será igual a zero.

\subsection{Equilibrio Tecnológico}

A característica crucial do modelo é a alocação de capital humano entre o setor de manufatura e de $\mathrm{P} \& \mathrm{D}$, pois sendo o mercado de fatores competitivo, este é o único fator comum entre ambos os setores. Isto é, assume-se que o capital humano é perfeitamente móvel e que os salários são flexíveis. Além disso, a alocação de equilíbrio é atingida quando a taxa de salário para o capital humano na manufatura, $\mathrm{w}_{\mathrm{hY}}$, é igual à taxa de salário para $\mathrm{O}$ capital humano no setor de P\&D, $\mathrm{w}_{\mathrm{EA}}$. É claro que se o mercado de traba- 
lho é competitivo, os salários para o capital humano, em ambos os setores, devem ser iguais aos seus produtos marginais. Derivando a equação (2) tem-se o salário do capital humano no setor de manufaturados, que é dado por:

$$
\omega_{\mathrm{HY}}=\frac{\partial \mathrm{Y}}{\partial \mathrm{H}_{\mathrm{Y}}}=\alpha \mathrm{H}_{\mathrm{Y}}^{(\alpha-1)} \mathrm{L}^{\beta}\left(\mathrm{Ax}^{\gamma}+\mathrm{A}^{*} \mathrm{~m}^{\gamma}\right)
$$

Usando o fato de que $\mathrm{x}=\mathrm{m}$, resolvendo a equação (10) para $\mathrm{L}^{\beta}$ e substituindo na expressão acima obtém-se:

$$
\omega_{\mathrm{HY}}=\frac{\alpha}{\gamma^{2}} \mathrm{H}_{\mathrm{Y}}^{-1}(\mathrm{~A}+\mathrm{A} *)_{\mathrm{Xr}}
$$

Desta equação, infere-se que o salário do capital humano alocado na manufatura está positivamente relacionado com os bens de capital, ou seja, quanto maior a quantidade de bens de capital utilizado na manufatura, maior o salário do capital humano nesse setor. Outrossim, $\omega_{\mathrm{h}} \mathrm{Y}$ também depende positivamente do estoque de conhecimento da economia.

Para se determinar o salário no setor de $\mathrm{P} \& \mathrm{D}$, deve-se obter o produto marginal do trabalho nesse setor. Então, considere a função lucro, $\pi_{\mathrm{P \& D}}$, do setor de P\&D, dada por:

$$
\pi_{\mathrm{P} \& \mathrm{D}}=\mathrm{P}_{\mathrm{A}} \dot{\mathrm{A}}-\omega_{\mathrm{HA}} \mathrm{H}_{\mathrm{A}}
$$

Derivando a expressão acima em relação a $\mathrm{H}_{\mathrm{A}}$, e utilizando a condição de primeira ordem para máximo e a equação (4), obtém-se o produto marginal do trabalho no setor de P\&D, que deve ser igual ao salário nesse setor, tal que:

$$
\omega_{\mathrm{HA}}=\mathrm{P}_{\mathrm{A}} \mathrm{A}_{\mathrm{A}} \delta
$$


Substituindo na expressão anterior o valor de $\mathrm{P}_{\mathrm{A}}$, obtido da equação (12), chega-se a:

$$
\omega_{H A}=(x+m *)\left(\frac{\alpha+\beta}{\gamma}\right) A_{A} \delta
$$

Conforme a equação (15), o salário do capital humano, alocado no setor de $\mathrm{P} \& \mathrm{D}$, está positivamente relacionado com o estoque de conhecimento e os bens de capital, de tal maneira que quanto maior o estoque de conhecimento ou de bens de capital na economia, maior a remuneração dos trabalhadores nesse setor. Observa-se também que quanto maior a elasticidade do capital $(\gamma)$ em relação ao produto do setor manufatureiro $(\mathrm{Y})$, menor o impacto nos salários decorrente de mudanças no estoque de capital ou de conhecimento. O equilíbrio tecnológico ocorre quando $\omega_{\mathrm{HY}}=\omega_{\mathrm{HA}}$, que pode ser expresso em termos do custo de oportunidade, $r$, como segue:

$$
\mathrm{r}=\frac{\delta}{\psi}\left[\frac{\left(\mathrm{x}+\mathrm{m}^{*}\right) \mathrm{A}_{\mathrm{A}}}{\left(\mathrm{A}+\mathrm{A}^{*}\right) \mathrm{x}}\right] \mathrm{H}_{\mathrm{Y}}
$$

onde $\psi=\alpha /[(\alpha+\beta) \gamma]>0$.

Alternativamente, utilizando as definições de $\mathrm{H}_{\mathrm{Y}}, \mathrm{x}$ e $\mathrm{m}^{*}$, dadas pelas respectivas expressões (6), (10) e (11), a equação (16) pode ser reescrita de forma a se obter $r$ em função da proporção de conhecimento da região, do capital humano empregado na manufatura e do trabalho não qualificado. Nestes termos, o custo de oportunidade do capital, derivado da condição de equilíbrio tecnológico, é dado por:

$$
r_{t c}=\frac{\delta}{\psi}\left\{\left[\frac{A_{A}}{A+A^{*}}\left(1+\left(\frac{H_{Y}^{*}}{H_{Y}}\right)^{\frac{\alpha}{\alpha+\beta}}\left(\frac{L^{*}}{L}\right)^{\frac{\beta}{\alpha+\beta}}\right)\right]\right\} H_{Y}
$$




\subsection{Lado da Demanda}

O comportamento dos indivíduos é descrito por um modelo do tipo Ramsey-Cass-Koopmans. Por simplicidade, assume-se que o agente representativo de ambas as regiões possui elasticidade de substituição intertemporal constante e igual $(1 / s)$, e que desconta sua utilidade futura a uma taxa constante de preferência $\rho$ e $\rho^{*}$, respectivamente para as regiões 1 e 2. Assim sendo, a função utilidade do indivíduo, que depende do consumo $(c)$, será:

$$
\mathrm{u}(\mathrm{c})=\frac{\mathrm{c}^{1-\sigma}}{1-\sigma}
$$

$\mathrm{O}$ agente representativo maximiza sua utilidade intertemporalmente considerando sua restrição orçamentária, que é dada pela equação diferencial:

$$
\dot{a}=\omega+r a-c-n a
$$

onde " a "representa os ativos e $\omega$ a renda do trabalho do agente econômico.

A solução para o problema de otimização fornece a seguinte equação denominada equação de Euler - para a trajetória de consumo da região l:

$$
\frac{\dot{\mathrm{c}}}{\mathrm{c}}=\frac{\mathrm{r}-\rho-\mathrm{n}}{\sigma}
$$

Por analogia, a equação para a trajetória de consumo da região 2 é dada por: 


$$
\frac{\mathrm{c}^{*}}{\mathrm{c}^{*}}=\frac{\mathrm{r}-\rho^{*}-\mathrm{n}}{\sigma}
$$

Considerando uma situação de autarcia, para derivar as taxas de crescimento das variáveis agregadas e, por conseguinte, das variáveis per capita para a região 1 , por exemplo, é necessário fazer as variáveis da região 2 iguais a zero, notar que $\mathrm{A}_{\mathrm{A}}=\mathrm{A}$ e também multiplicar ambos os lados das equações (1) e (2) por $\mathrm{l} / \mathrm{P}$ a fim de expressar $\mathrm{Y}$ e $\mathrm{K}$ em termos per capita. Além disso, considere a hipótese de que dentro do conjunto de bens de capital as condições de oferta e demanda são as mesmas, como discutida no início da seção 2.2. A log-diferenciação de ambas as equações dá origem a taxa de crescimento:

$$
\mathrm{g}=\frac{\dot{\mathrm{c}}}{\mathrm{c}}=\frac{\dot{\mathrm{y}}}{\mathrm{y}}=\frac{\dot{\mathrm{k}}}{\mathrm{k}}+\chi=\frac{\dot{\mathrm{A}}}{\mathrm{A}}+\chi-\mathrm{n}=\delta \mathrm{H}_{\mathrm{A}}+\chi-\mathrm{n}
$$

onde variáveis minúsculas indicam valores per capita, $\chi=\alpha \frac{\dot{\mathrm{H}}_{\mathrm{Y}}}{\mathrm{H}_{\mathrm{Y}}}+\beta \frac{\dot{\mathrm{L}}}{\mathrm{L}} \quad \mathrm{e}$ $\chi>0$.

Combinando a equação (20.a) e (21), obtém-se a taxa de juro de equilíbrio do lado da demanda:

$$
r_{D}=\sigma g+\rho+n
$$

Observa-se que um aumento do emprego de capital humano em $\mathrm{P} \& \mathrm{D}$, na região 1 , conforme a equação (21), provoca uma elevação na taxa de crescimento e, conseqüentemente, da taxa de juro de acordo com a equação (22). 


\subsection{Equilibrio Geral}

Por simplicidade, mas sem perda de generalidade, pode-se derivar o equilíbrio geral deste modelo, em autarcia, de forma a se estabelecer um marco referencial de análise. Assim, considerando as variáveis da região 2 iguais a zero, a taxa de juro e a alocação de capital humano de equilíbrio podem ser obtidas para a região 1 , como segue.

O equilíbrio tecnológico, descrito pela equação (17), é agora dado por:

$$
\mathrm{r}_{\mathrm{tc}}=\frac{\delta}{\psi}\left(\mathrm{H}-\mathrm{H}_{\mathrm{A}}\right)
$$

A equação (23) descreve a curva de equilíbrio tecnológico, $r_{t c}$, mostrando as combinações de $\mathrm{r}$ e $\mathrm{H}_{\mathrm{A}}$ que asseguram o equilíbrio no mercado de capital humano. Essa curva reflete que o produto marginal do capital humano no setor de manufaturados é igual ao produto marginal no setor de P\&D. Como a inclinação da curva $r_{t c}$, em relação a $H_{A}$, é negativa, ${ }^{12}$ um aumento de capital humano no setor de P\&D, e conseqüente redução de capital humano no setor de manufaturados, implica queda da taxa de juro. Isto ocorre devido ao fato de que a redução de capital humano no setor de manufaturados reduz o produto marginal do capital, que em equilíbrio deve se igualar à taxa de juro (ver Figura 1).

A equação (22), que mostra a taxa de juro de equilíbrio do lado da demanda, pode ser reescrita como segue:

$$
r_{D}=\sigma\left(\delta H_{A}+\chi-n\right)+\rho
$$

12 Relembrando que $\psi>0$ e $\delta>0$. 


\section{FIGURA I - TAXA DE JURO E ALOCAÇÃO DE $H_{A}$ DE EQUILÍBRIO}

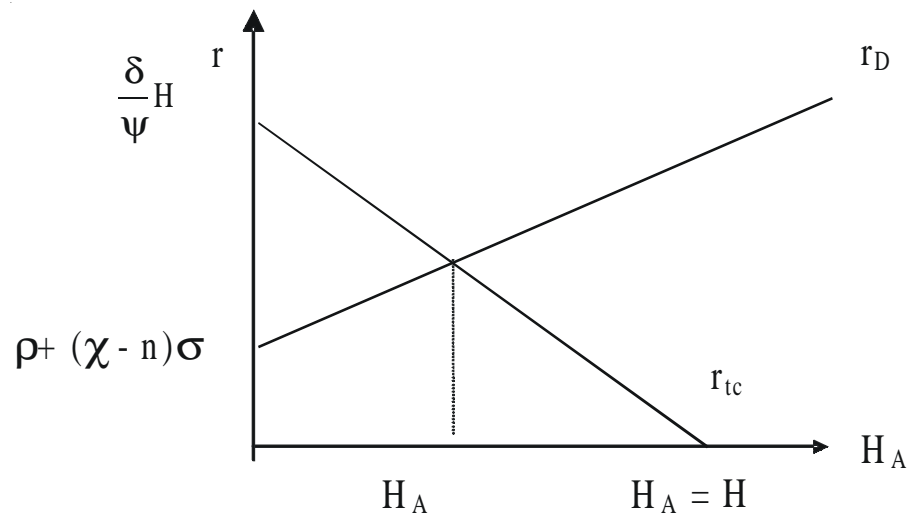

Observe que a inclinação da curva $\mathrm{r}_{\mathrm{D}}$, em relação ao capital humano alocado no setor de P\&D, é positiva, como foi demonstrado na Figura 1. Assim, um aumento do emprego de capital humano em P\&D, na região 1 , induzirá a uma elevação da taxa de juro de equilíbrio do lado da demanda. O juro que assegura o ótimo das famílias deve aumentar devido ao fato de que o aumento de capital em P\&D implica maiores taxas de crescimento da economia. Para que isto ocorra, as famílias devem escolher mais consumo no futuro - aumentar a poupança no presente - e para tal a taxa de juro deve elevar-se para que as famílias tenham incentivos para poupar.

Em equilíbrio, onde tanto a alocação de $\mathrm{H}_{\mathrm{A}}$ quanto a utilidade dos agentes privados estão sendo otimizadas, essas diferentes taxas de juros devem se igualar, isto é: $r_{t c}=r_{D}$. Portanto, combinando (22.a) e (23) e efetuando algumas manipulaçôes algébricas, obtém-se a taxa de crescimento de equilíbrio geral da economia:

$$
\mathrm{g}=\frac{\delta \mathrm{H}_{\mathrm{Y}}-\psi(\rho+\mathrm{n})}{\psi \sigma}
$$

Desde que uma taxa de crescimento de equilíbrio negativa não tem sentido econômico, é necessário impor que g $>0$. Isto implica que: 


$$
\mathrm{H}_{\mathrm{Y}}>\frac{\psi(\rho+\mathrm{n})}{\delta} \Rightarrow H_{Y}>\frac{\alpha}{(\alpha+\beta) \gamma} \frac{(\rho+n)}{\delta}
$$

Esta expressão não pode ser literalmente comprovada. Todavia, assumindo valores factíveis para os parâmetros acima pode-se deduzir que a desigualdade de fato se verifica. Ela só não se verificaria para valores limites de $\gamma$, ou seja, 0 e 1 , ou caso $\delta$ fosse aproximadamente igual a zero, o que faria com que a expressão acima divergisse. Entretanto, tais valores não são, em geral, admitidos na literatura, que considera como factível um intervalo para o $\gamma$ entre 0.30 e 0.75 . Ademais, o valor do parâmetro $\delta$, que representa a produtividade do capital humano no setor de $\mathrm{P} \& \mathrm{D}$, também deve ser significativamente diferente de zero. Isto posto, desde que os parâmetros assumam valores factíveis, o lado direito da expressão acima tende para zero, isto é: $\mathrm{H}_{\mathrm{Y}} \tilde{>} 0$. Em palavras, a expressão acima implica que para que a taxa de crescimento de equilíbrio (g) seja positiva é necessário que algum capital humano esteja sendo alocado no setor de manufaturados, ou seja, o setor de P\&D não pode empregar toda a mão-de-obra qualificada da economia.

\section{EFEITOS DA INTEGRAÇÃO SEM DIFUSÃO DE CONHECI- MENTO}

A análise será efetuada considerando que todas as barreiras existentes ao comércio e ao fluxo de capitais, quer sejam tarifárias, tributárias, sanitárias etc., sejam removidas de tal forma que ocorra a integração comercial e financeira dentro do país. Entretanto a falta de canais de comunicação, instituições capazes de armazenar, processar e difundir informações, capital humano, capital físico etc., impedem a difusão de conhecimento e o setor de P\&D de cada região terá à sua disposição apenas seu próprio estoque de conhecimento, não incorporando o conhecimento acumulado na outra região. Em outras palavras, isto significa que à aquisição de um bem de capital importando não implica que o conhecimento nele embutido seja absorvido e então aplicado na produção de novos projetos, isto é, não é possível 
gerar novo conhecimento (inovação) simplesmente pela posse de um novo bem de capital. Portanto, pode-se escrever: $A=A_{A}$.

Como visto anteriormente, a realocação de capital humano entre os setores de manufaturados e de $\mathrm{P} \& \mathrm{D}$ depende dos salários relativos, dado o nível de produção e taxa de juro. Foi também mostrado que: $\mathrm{p}=\mathrm{p}^{*}, \mathrm{x}=\mathrm{m}$, $\mathrm{x}^{*}=\mathrm{m}^{*}$. Assim, como a proposta do trabalho é analisar a integração entre desiguais, será considerada a hipótese de que a região 1 aloca uma maior quantidade de capital humano no setor de $\mathrm{P} \& \mathrm{D}\left(\mathrm{H}_{\mathrm{A}}>\mathrm{H}_{\mathrm{A}}^{*}\right)$ e que tem um estoque de conhecimento maior que o da região $2\left(A>A^{*}\right)$. Dessa maneira, tem-se necessariamente que:

$$
\frac{\mathrm{A}}{\left(\mathrm{A}+\mathrm{A}^{*}\right)} \in(1 / 2,1)
$$

Por simplicidade de análise, assume-se que o número de trabalhadores não qualificados é igual em ambas as regiões, isto é: $\mathrm{L}=\mathrm{L}^{*}$. Portanto, devido às hipóteses de que no momento da integração a região 1 está utilizando mais capital humano em P\&D do que a 2, e que as populações de ambas as regiões são iguais, tem-se que $\mathrm{H}_{\mathrm{Y}}<\mathrm{H}_{\mathrm{Y}}^{*}$.

Isso posto, a realocação de capital humano entre o setor de manufaturados e de P\&D, em função da integração, depende de como os salários relativos serão afetados pela nova estrutura de produção da economia. A partir das considerações acima, a equação (17), derivada da condição de igualdade entre os salários na manufatura e no setor de P\&D, no momento da integração, é dada por:

$$
r_{t c}=\frac{\delta}{\psi}\left[\frac{A}{A+A^{*}}\left(1+\frac{H_{Y}^{*}}{H_{Y}}\right)^{\frac{\alpha}{\alpha+\beta}}\right] H_{Y}
$$

Nota-se nesta equação que o termo entre chaves é maior que 1 , isso porque o termo entre parênteses é maior do que 2. Comparando a expressão acima 
com a equação (23), observa-se que a taxa de juro de equilíbrio tecnológico, que deve vigorar pós-integração, é maior que a do período onde as economias não eram integradas. Desta forma, supondo que a taxa de juro não mude instantaneamente, ou seja, dada a taxa de juro $r$ de autarcia, tem-se:

$$
r_{\text {autarcia }}<\frac{\delta}{\psi}\left[\frac{A}{A+A^{*}}\left(1+\frac{H_{Y}^{*}}{H_{Y}}\right)^{\frac{\alpha}{\alpha+\beta}}\right] H_{Y}
$$

Por isso, conclui-se que $\omega_{\mathrm{HA}} / \omega_{\mathrm{HY}}$ é maior do que 1 , ou seja, o salário do capital humano no setor de P\&D é maior que no setor de manufaturados.

Portanto, na região 1 ocorre a migração de capital humano do setor de manufaturados para o setor de $\mathrm{P} \& \mathrm{D}$, já que os salários daquele primeiro setor são menores que no segundo. Por conseqüência, o produto marginal do capital humano no setor de manufaturados aumenta, provocando um aumento dos salários nesse setor, enquanto o salário no setor de P\&D mantém-se constante já que seu produto marginal não é alterado. Dessa maneira, o equilíbrio é novamente atingido, ou seja, ocorre a equalização. Tal processo é verificado de forma inversa na região 2 .

Após o impacto inicial da integração, acarretando na região 1 um aumento na alocação de capital humano em P\&D e uma redução na região 2, a migração de mão-de-obra entre regiões é que determinará a nova estrutura produtiva da economia, visto que para atingir uma nova condição de equilíbrio é necessário que os salários se equalizem entre setores e também entre as regiões do país.

Assim sendo, uma vez que a região 1 têm uma menor dotação de capital humano alocada no setor de manufaturados que a região 2, o produto marginal de $\mathrm{H}_{\mathrm{Y}}$ é maior que de $\mathrm{H}_{\mathrm{Y}}^{*}$. Isto provoca a migração de capital humano do setor de manufaturados da região 2 para a região 1 , de tal forma que os salários se equalizem no setor de manufaturados e ambas as regiões continuem produzindo bens manufaturados. Dada a simetria das funções de produção, pode-se demonstrar que pós-integração e em equilí- 
brio a demanda do setor de manufaturados por capital humano e igual em ambas as regiões, isto é, $H_{Y}=H_{Y}^{*}$.

Por sua vez, em função da hipótese de ausência de difusão de conhecimento entre as regióes, o setor de P\&D apresenta uma estrutura mais complexa para se analisar. Considere as equações abaixo - derivadas da equação (15) - que descrevem o salário do capital humano alocado no setor de P\&D das regiões 1 e 2 , respectivamente.

$$
\begin{aligned}
& \omega_{H A}=P_{A} \delta A \\
& \omega_{H A}^{*}=P_{A}^{*} \delta * A^{*}
\end{aligned}
$$

Em função da mobilidade de bens de capital entre as regiões e da equalização da taxa de juros pós-integração, o produto marginal dos bens de capital deve igualar-se entre as regióes. Por sua vez, isto implica que $\left(x+\mathrm{m}^{*}\right)=$ $\left(\mathrm{x}^{*}+\mathrm{m}\right)$ e que o preço da patente também se equalizará entre as regiões. Portanto, a expressão a seguir denota a relação entre os salários no setor de P\&D das regiões 1 e 2.

$$
\varepsilon=\frac{\omega_{H A}}{\omega_{H A}^{*}}=\frac{\delta A}{\delta * A^{*}}
$$

$\mathrm{Na}$ equação (27), se $\varepsilon=1$, implica que os salários do capital humano nas regiões 1 e 2 são iguais; se $\varepsilon>1$, indica que o salário no setor de $P \& D$ da região 1 é maior que o da região 2 , e se $\varepsilon<1$, indica que o salário no setor de $P \& D$ da região 1 é menor que o da região 2.

Usando a solução das equações diferenciais (4) e (5) para A e $A^{*}$, a equação (27) pode ser reescrita da seguinte forma:

$$
\varepsilon=\frac{\delta A(0) \exp \left(\int \delta H_{A} d t\right)}{\delta * A(0) * \exp \left(\int \delta * H_{A}^{*} d t\right)}
$$


Desde que $H_{A}$ e $H_{A}^{*}$ dependem de $\mu$ e $\lambda$, observa-se, na equação acima, que a política de qualificação de mão-de-obra $(\mu$ e $\lambda)$ e os parâmetros de produtividade $\left(\delta\right.$ e $\left.\delta^{*}\right)$ das regiões poderão afetar a relação entre os salários no setor de P\&D. Assim, serão analisados diversos cenários hipotéticos. Vale ressaltar que se está considerando que as políticas de qualificação de mão-de-obra consideradas a partir daqui passam a vigorar somente após a integração, ou seja, elas não necessariamente eram implementadas no período pré-integração. Por simplicidade, mas sem perda de generalidade, considere que "se está no tempo 0" no momento da integração. Dessa maneira, em função das hipóteses feitas acima, o estoque de conhecimento inicial da região 1 é maior que da região 2 , isto é, $\mathrm{A}(0)>\mathrm{A}(0)^{*}$.

\subsection{Taxas Iguais de Qualificação de Mão-de-Obra $(\lambda=\mu)$}

Nesta situação, supõe-se que as regiões qualifiquem parcelas iguais da população que está surgindo. Todavia, como o parâmetro produtividade afeta as análises, serão analisados os casos abaixo.

\section{a) $\delta=\delta^{*}$ ou $\delta>\delta^{*}$}

Neste caso está-se considerando a possibilidade da produtividade da região 1 ser maior ou igual ao parâmetro produtividade da região 2 porque os resultados obtidos são similares quando ocorre o inverso. Assim, desde que não ocorra a difusão de conhecimento, o salário do capital humano no setor de P\&D da região 1 será maior que o salário da região 2 , ou seja, de acordo com a equação (27.a') $\varepsilon>1$. Isto causará a migração de capital humano da região 2 para a região 1 neste setor. Portanto, o processo de migração continua de tal forma que a região 2 fica completamente especializada em manufaturados, paralisando a produção de novos projetos, enquanto a região 1 fica diversificada em produtos manufaturados e em P\&D. Formalizando, denote-se a proporção de projetos da região 1 por:

$$
\theta_{A}=A /\left(A+A^{*}\right)
$$


Como a região 2 cessa a produção de novos projetos, isso implica que: ${ }^{13}$

$$
\operatorname{Lim}_{t \rightarrow \infty} \theta_{A}=1
$$

Log-diferenciando a equação (25), obtém-se a taxa de mudança da proporção de projetos, dada por:

$$
\frac{\dot{\theta}_{A}}{\theta_{A}}=\frac{\dot{A}}{A}-\frac{\dot{A}+\dot{A}^{*}}{A+A^{*}}
$$

Usando as equações (4) e (5) e como sem difusão de conhecimento $\mathrm{A}=\mathrm{A}_{\mathrm{A}}$, obtém-se:

$$
\frac{\dot{\theta}_{A}}{\theta_{A}}=\left(1-\theta_{A}\right)\left(\delta H_{A}-\delta^{*} H_{A}^{*}\right)
$$

A proporção de projetos da região $\mathrm{l}$ aumenta tanto quanto ela usa mais $\mathrm{H}_{\mathrm{A}}$ no setor de P\&D. Esse processo cessa quando $\theta_{A}=1$, pois nesse caso a região 2 está completamente especializada na produção de manufaturados e toda a invenção de novos projetos é devido à região 1 .

A seguir, serão verificados os impactos da integração econômica nacional na trajetória de crescimento do estoque de capital e do produto de ambas as regiões, dadas as hipóteses acima.

i) Impacto no Produto e no Estoque de Capital da Região 1

Devido à hipótese de que dentro do mercado de bens de capital, isto é, $\mathrm{x}(\mathrm{i})$, $m(j), x(i)^{*}, m(j)^{*}$, as condições de oferta e demanda são as mesmas, e que

$13 \theta_{A}=\frac{A}{A+A^{*}}=\frac{1}{1+A^{*} / A}$. Desde que A está crescendo ao longo do tempo e $A^{*}$ está fixo, já que a região 2 cessa a produção de novos projetos, aplicando o limite nesta expressão, quando "t" tender para o infinito, ela tenderá para 1. 
em equilíbrio os preços e quantidades de cada tipo de bem de capital são iguais, em um dado momento do tempo é possível resolver as integrais das equações (1), (2) e (3). ${ }^{14}$ Assim, resolvendo a equação (1) obtém-se: $\mathrm{K}=\mathrm{Ax}+\mathrm{A}^{*} \mathrm{~m}$. Desde que a região 2 cesse sua produção de novos projetos, $\dot{\mathrm{A}}^{*}=0$. Log-diferenciando esta última expressão obtém-se:

$$
\frac{\dot{K}}{K}=\frac{\dot{A}}{A+A^{*}} \quad \text { onde } \quad \operatorname{Lim}_{t \rightarrow \infty} \frac{\dot{K}}{K}=\frac{\dot{A}}{A}
$$

Portanto, na região 1 a taxa de crescimento do estoque de capital tende assintoticamente para a taxa de crescimento de novos projetos produzidos por ela desde que os novos projetos da região 2 se tornem negligenciáveis ao longo do tempo quando comparados aos da região l. Da mesma maneira, o estoque de capital per capita, $\mathrm{k}=\mathrm{K} / \mathrm{P}$, cresce assintoticamente à taxa:

$$
\lim _{t \rightarrow \infty} \frac{\dot{k}}{k}=\frac{\dot{A}}{A}-n
$$

O impacto na taxa de crescimento do produto pode ser obtido da função de produção da manufatura, dada pela equação (2), a qual, em função das hipóteses citadas acima, pode ser reescrita da seguinte forma:

$$
Y=H_{Y}^{\alpha} L^{\beta}\left(A x^{\gamma}+A^{*} m^{\gamma}\right)
$$

14 E importante ressaltar que se está assumindo que não há difusão de conhecimento; todavia, considera-se que ocorre a integração comercial e financeira, tal que os bens de capital podem circular livremente entre as regiões. Portanto, as equaçóes (1), (2) e (3) permanecem válidas para descrever a estrutura produtiva das regióes. 
Log-diferenciando essa expressão, utilizando o fato de que e calculando o seu limite, tem-se:

$$
\operatorname{Lim}_{t \rightarrow \infty}\left(\frac{\dot{Y}}{Y}\right)=\beta \frac{\dot{L}}{L}+\alpha \frac{\dot{H}_{Y}}{H_{Y}}+\frac{\dot{A}}{A}
$$

Assintoticamente a taxa de crescimento do produto per capita, $\mathrm{y}=\mathrm{Y} / \mathrm{P}$, é dada por:

$$
\underset{t \rightarrow \infty}{\operatorname{Lim}\left(\frac{\dot{y}}{y}\right)}=\beta \frac{\dot{L}}{L}+\alpha \frac{\dot{H}_{Y}}{H_{Y}}+\frac{\dot{A}}{A}-n
$$

Como a região 1 utiliza mais $\mathrm{H}_{\mathrm{A}}$ em $\mathrm{P} \& \mathrm{D}$, ao longo da nova trajetória de crescimento balanceado, a taxa de crescimento de novos projetos é maior após a integração. Portanto, maiores serão as taxas de crescimento do produto e do estoque de capital per capita.

ii) Impacto no Produto e no Estoque de Capital da Região 2

Os resultados para a região 2 são obtidos de forma análoga aos da região 1 . Assim sendo, apenas as equações resultantes são apresentadas:

$$
\operatorname{Lim}_{t \rightarrow \infty} \frac{\dot{k}^{*}}{k^{*}}=\frac{\dot{A}}{A}-n
$$

$\mathrm{e}$

$$
\operatorname{Lim}_{t \rightarrow \infty}\left(\frac{\dot{y^{*}}}{y^{*}}\right)=\beta \frac{\dot{L^{*}}}{L^{*}}+\alpha \frac{\dot{H}_{Y}^{*}}{H_{Y}^{*}}+\frac{\dot{A}}{A}-n
$$


As taxas de crescimento do estoque de capital e do produto per capita da região 2, ao longo do tempo, é determinada pela taxa de crescimento do estoque de conhecimento da região 1. Assim, o crescimento da região 2 passa a depender, sobremaneira, do comportamento da economia da região 1 .

Em síntese, pode-se destacar dois resultados centrais da integração: i) as taxas de crescimento do estoque de capital per capita de ambas as regiões são iguais, sendo que a integração tem efeitos positivos sobre as taxas de crescimento de $\mathrm{k} \mathrm{e}^{*}$, pois a região $\mathrm{l}$, que determina a taxa de crescimento das duas regiões, está empregando mais capital humano em P\&D e, com isso, a taxa de crescimento de novos projetos é também maior; ii) o produto per capita é afetado de duas formas: a primeira se dá via aumento do estoque de conhecimento, já que a região l está utilizando mais HA no setor de P\&D e, com isso, criando projetos a uma taxa maior que antes da integração. Esse efeito é igual para ambas as economias. A outra forma é a alocação de mão-de-obra qualificada na manufatura. Esta apresenta efeitos diferenciados em cada região em função da migração de capital humano entre os setores manufaturados e de P\&D. Conforme discutido acima, na região 1 ocorre a migração de capital humano da manufatura para P\&D e de forma inversa na região 2 . Esse movimento é responsável pelo crescimento do produto per capita da região 2 a taxas mais elevadas que da região 1 no início do processo de integração. Porém, assintoticamente essas taxas convergem para um mesmo patamar de equilíbrio.

Discutir-se-á a seguir os impactos da integração econômica nacional na trajetória de consumo das regiões que estão se integrando.

iii) Impacto no Consumo das Regiões 1 e 2

Em equilíbrio, o consumo per capita cresce à mesma taxa que o produto per capita. Assim, como a integração tem efeitos positivos sobre a taxa de crescimento do produto per capita de ambas as regiões, a taxa de crescimento do consumo per capita é também afetada de forma positiva nas duas regiões após a integração. Outra forma de se constatar tal efeito é avaliar a taxa de 
juro pós-integração. Como foi visto, ela se eleva, e de acordo com as equações (20.a) e (20.b) a taxa de crescimento do consumo per capita deve também elevar-se desde que as taxas de preferência continuem as mesmas.

\section{b) $\delta<\delta^{*}$}

Nesse cenário, onde a produtividade do capital humano no setor de P\&D da região 1 é menor que a da região 2, o valor da equação (27.a') é ambíguo, já que o menor estoque de conhecimento da região 2 , no momento da integração, $\mathrm{A}(0)>\mathrm{A}(0)^{*}$, pode ser ou não compensado pela maior produtividade do seu capital humano, $\delta<\delta *$. Todavia, essa ambigüidade pode ser questionada com base na intuição de que regiões relativamente atrasadas têm produtividade também menor, o que tornaria pouco plausível a possibilidade de $\delta<\delta^{*}$.

\subsection{Taxa de Qualificação de Mão-de-Obra da Região 2 Maior que da Região 1 $(\lambda>\mu)$}

Supõe-se aqui que a região 2 está qualificando mais capital humano do que a região 1 no período pós-integração. Como no item anterior, a magnitude da produtividade do capital humano e das taxas de qualificação afeta os resultados. Assim, serão analisados diferentes cenários, como segue.

\section{a) Suponha que $\delta=\delta$ *}

Considera-se neste caso que a produtividade do capital humano no setor de P\&D é igual em ambas as regiões. Para avaliar esse cenário é necessário avaliar como $\varepsilon$ se comporta no tempo. Usando a equação (6), a hipótese de populações iguais e o fato que, em equilíbrio, a demanda do setor de manufaturados por capital humano é igual em ambas as regiões, $H_{Y}=H_{Y}^{*}$, a equação (27.a') pode ser reescrita da seguinte forma:

$$
\varepsilon=\frac{\delta \mathrm{A}(0) \exp \left(\int\left[\mathrm{P}(0)\{\delta \mu-\delta * \lambda\} \exp (\mathrm{nt})-\left\{\delta-\delta^{*}\right\} \mathrm{H}_{\mathrm{y}}\right] \mathrm{dt}\right)}{\delta^{*} \mathrm{~A}(0)^{*}}
$$


Calculando o limite da equação (27.b), observa-se que $\varepsilon \rightarrow 0$. Isto mostra que desde que não ocorra uma migração instantânea de capital humano do setor de P\&D no momento da integração, com o contínuo aumento da oferta de capital humano e o conseqüente aumento do estoque de conhecimento na região 2 , os salários da região 2 superam os da região 1 ao longo do tempo, provocando a migração de capital humano do setor de P\&D da região 1 para a região 2 , paralisando, em conseqüência, a produção de novos projetos na região 1 .

Portanto, o limite da equação (27.b) tenderá a zero quando " $t$ " tender para o infinito, implicando que a região 2 passa a dominar a produção de novos projetos da economia. Dessa maneira, a região 2 - que possuía um estoque de conhecimento menor que o da região 1 antes da integração -, por meio de uma vigorosa política de qualificação de mão-de-obra, pode superar o atraso tecnológico e, como se demonstrará a seguir, passará a conduzir o processo de crescimento do país.

As trajetórias do estoque de capital e do produto per capita das regiões são derivadas de forma análoga ao do caso anterior e, portanto, não será novamente demonstrado. A diferença verificada nessas equações em relação ao caso anterior é que agora o crescimento do estoque de capital e do produto per capita da região 1 e o produto per capita da região 2 são governados, respectivamente, pela taxa de crescimento do estoque de conhecimento da região 2 como segue:

$$
\begin{aligned}
& \operatorname{Lim}_{t \rightarrow \infty}\left(\frac{\dot{k}}{k}\right)=\frac{\operatorname{Lim}}{t \rightarrow \infty}\left(\frac{\dot{k^{*}}}{k^{*}}\right)=\frac{\dot{A^{*}}}{A^{*}}-n \\
& \operatorname{Lim}\left(\frac{\dot{y}}{y}\right)=\beta \frac{\dot{L}}{L}+\alpha \frac{\dot{H}_{Y}}{H_{Y}}+\frac{\dot{A}^{*}}{A^{*}}-n \\
& t \rightarrow \infty
\end{aligned}
$$




$$
\operatorname{Lim}_{t \rightarrow \infty}\left(\frac{\dot{y^{*}}}{y^{*}}\right)=\beta \frac{\dot{L^{*}}}{L^{*}}+\alpha \frac{\dot{H}_{Y}^{*}}{H_{Y}^{*}}+\frac{\dot{A^{*}}}{A^{*}}-n
$$

Não se avaliará o comportamento do consumo das regiões já que a análise é idêntica ao apresentado no item 2.2 deste trabalho.

\section{b) Suponha que $\delta>\delta^{*}$}

Devido ao fato da produtividade do capital humano na região 1 ser maior que da região 2 , novamente tem-se uma situação ambígua e não se pode deduzir a magnitude da equação (27.b), visto que a maior produtividade do capital humano da região 1 pode compensar ou não a maior taxa de qualificação de mão-de-obra da região 2 . No entanto, se o valor de $\lambda$ for significativamente superior ao de $\mu$, de tal maneira que compense o diferencial de produtividade, o limite da equação (27.b) tenderá para 0 e deverá ocorrer a migração de mão-de-obra da região 1 para a região 2 , o que provocará a especialização da região 1 , que deixará de produzir novos projetos. Se isto acontecer, as trajetórias de crescimento do produto e do capital de ambas regiốes passam a ser governadas pela região 2 .

\section{c) Suponha que $\delta<\delta^{*}$}

Neste caso, mesmo que as taxas de qualificação de capital humano, $\lambda$ e $\mu$, sejam muito próximas, o diferencial de produtividade pode compensar a diferença na dotação inicial de conhecimento e de capital humano no setor de P\&D da região 2 , de tal modo que $\varepsilon<1$ [equação $\left(27^{\prime \prime}\right)$ ] e a região 2 passará a governar as trajetórias de crescimento do produto e do capital das regiốes 1 e 2 .

\subsection{Avaliação dos Resultados da Integração sem Difusão de Conbecimento}

Os cenários analisados mostram que regiôes menos desenvolvidas, ao se integrarem com outras regiões, não necessariamente se especializarão na 
produção de bens manufaturados. A especialização ocorrerá dependendo da estrutura econômica - em específico da produtividade - das regióes que estão se integrando, e também de como a região atrasada passará a qualificar mão-de-obra após a integração. Em outras palavras, se a dotação de conhecimento de uma das regióes for significativamente superior à da outra e não se atacar o problema do atraso tecnológico por meio de um vigoroso processo de qualificação de capital humano, na ausência de difusão de conhecimento provavelmente deverá ocorrer a especialização em manufatura da região atrasada.

\section{EFEITOS DA INTEGRAÇÃO COM DIFUSÃA DE CONHECI- MENTO}

A hipótese de difusão de conhecimento implica a existência de uma rede complexa de transmissão de conhecimento entre os institutos de pesquisa, universidades etc., quer sejam públicas ou privadas, na região integrada, a fim de que qualquer avanço tecnológico seja plenamente compartilhado com os profissionais da área de $\mathrm{P} \& \mathrm{D}$. Por simplicidade, assume-se que não ocorre redundância, de tal forma que pós-integração o estoque de conhecimento das regiões seja equivalente à soma dos conhecimentos individuais. ${ }^{15}$ Isto é: $A_{A}=A_{A}^{*}=A+A^{*}$. Assim, as equações (4) e (5) serão descritas agora por:

$$
\begin{aligned}
& \dot{A}=\delta H_{A}\left(A+A^{*}\right) \\
& \dot{A}^{*}=\delta^{*} H_{A}^{*}\left(A+A^{*}\right)^{*}
\end{aligned}
$$

15 Naturalmente, uma formulação mais realista deveria considerar a possibilidade de redundância de conhecimento e, portanto, com integração seguida de difusão de conhecimento o estoque de conhecimento disponível para pesquisas deveria ser dado pela soma do conhecimento das regióes menos o conhecimento que é comum em ambas. Em termos de conjuntos pode-se escrever $A_{A}=A_{A}^{*}=\left(A Y A^{*}\right)-\left(A \cap A^{*}\right)$. Todavia, o fato de se assumir que não há redundância não invalida as análises, na medida em que somente a magnitude das variáveis é afetada, sem, no entanto, afetar a tendência das mesmas. 
Desta forma, a produção do setor P\&D aumentará em ambas as regiões devido ao aumento do estoque de conhecimento disponível para os pesquisadores.

Substituindo o valor de $A_{A}$ na equação (15), gera-se a nova equação do salário no setor de P\&D da região 1 . Por analogia, o salário da região 2 é também obtido. As equações a seguir representam, respectivamente, os salários das regiões 1 e 2 .

$\omega_{H A}=\left(\frac{\alpha+\beta}{\gamma}\right)\left(x+m^{*}\right)\left(A+A^{*}\right) \delta ; \quad \omega_{H A}^{*}=\left(\frac{\alpha+\beta}{\gamma}\right)(x *+m)\left(A+A^{*}\right) \delta^{*}$.

Relembrando que com a integração tem-se $\left(x+m^{*}\right)=\left(x^{*}+m\right)$, a expressão $\varepsilon=\frac{\omega_{H A}}{\omega_{H A}}=\frac{\delta}{\delta *}$ denota a relação entre os salários no setor de $\mathrm{P} \& \mathrm{D}$ das regiões l e 2 considerando a hipótese de difusão de conhecimento.

Dessa maneira, vê-se que as políticas de qualificação de capital humano não afetam a relação de salários entre as regiões, isto porque um aumento da alocação de capital humano em P\&D em uma das regióes implica aumento de seu estoque de conhecimento que, em função da difusão de conhecimento, é compartilhado com a outra região, fazendo com que ambas as regiões incorporem os avanços gerados por qualquer uma delas.

A particularidade desse caso reside no problema do carona ou "free rider". Não faz parte do escopo deste trabalho analisar como a mão-de-obra foi qualificada, porém esta tarefa é geralmente delegada ao governo, o qual incorre em custos para tal. Assim, a região que optasse por qualificar menos mão-de-obra também incorreria em menores custos de qualificação, apesar de incorporar os avanços obtidos. Este fato poderá gerar distorções na alocação de recursos e desestimular a realização de gastos em qualificação pelas regiões envolvidas se não houver um desenho ótimo da política de qualificação de capital humano dentro do país. Como discutido acima, o elemento central para explicar comportamento dos salários é apenas a 
produtividade do trabalho alocado em P\&D. Assim, estudar-se-á a seguir dois cenários a respeito da produtividade do capital humano nas regiões.

\subsection{Produtividade do Capital Humano Igual nas Regiões $\left(d=d^{*}\right)$}

Após a integração econômica, a produção do capital humano no setor de P\&D torna-se igual e aumenta em ambas as regiões, de modo que os salários também tornam-se iguais, $\omega_{\mathrm{HA}}=\omega_{\mathrm{HA}}^{*}$. Devido à hipótese de mobilidade de capital humano entre os setores de manufaturados e de P\&D e entre regiões, também ocorre a equalização intersetorial dos salários, sendo que $\omega_{\mathrm{HY}}=\omega_{\mathrm{HY}}^{*}$

Portanto, mesmo que antes da integração as regiões tenham dotaçóes de conhecimento diferentes, ambas continuam engajadas na atividade de P\&D já que nenhuma delas perde competitividade; ao contrário, tornam-se mais produtivas devido ao aumento do estoque de conhecimento disponível para seus pesquisadores. Para demonstrar isto, basta derivar as funções de produção do setor de P\&D em relação ao capital humano $\left(\mathrm{H}_{\mathrm{A}}\right)$, dadas pelas equações (4), (5), (4.a) e (5.a), e comparar a produtividade marginal do trabalho no período pós-integração com os valores do período préintegração, como se apresenta no Quadro 1.

QUADRO 1 - PRODUTIVIDADE MARGINAL DO CAPITAL HUMANO NO SETOR DE P\&D NO PERÍODO PRÉ E PÓSINTEGRAÇÃO

\begin{tabular}{ccc}
\hline Região & Pré-integração & Pós-integração \\
\hline 1 & $\frac{\partial \dot{A}}{\partial H_{A}}=\delta A$ & $\frac{\partial \dot{A}}{\partial H_{A}}=\left(A+A^{*}\right) \delta$ \\
2 & $\frac{\partial \dot{A^{*}}}{\partial H_{A}^{*}}=\delta A^{*}$ & $\frac{\partial \dot{A}^{*}}{\partial H_{A}^{*}}=\left(A+A^{*}\right) \delta$ \\
\hline
\end{tabular}

Note que por hipótese $\delta=\delta^{*}$. 
Por sua vez, a taxa de crescimento de novos projetos do país é agora dada por:

$$
\frac{\dot{\mathrm{A}}+\dot{\mathrm{A}}^{*}}{\mathrm{~A}+\mathrm{A}^{*}}=\left(\mathrm{H}_{\mathrm{A}}+\mathrm{H}_{\mathrm{A}}^{*}\right) \delta
$$

Essa taxa é maior que a taxa de crescimento de novos projetos no período pré-integração, que era dada por uma combinação linear do crescimento de cada região. Portanto, a integração tem efeitos positivos sobre a produção de novos projetos, de tal modo que a economia passa a produzir mais bens de capital após a integração.

A taxa de crescimento do capital per capita, obtida anteriormente de forma similar, é igual para ambas as regióes e dada por:

$$
\frac{\dot{\mathrm{k}}}{\mathrm{k}}=\frac{\dot{\mathrm{k}} *}{\mathrm{k}^{*}}=\frac{\dot{\mathrm{A}}+\dot{\mathrm{A}^{*}}}{\mathrm{~A}+\mathrm{A}^{*}}-\mathrm{n}
$$

As equações das trajetórias do produto das regiões 1 e 2 , são, respectivamente:

$$
\begin{aligned}
& \frac{\dot{\mathrm{y}}}{\mathrm{y}}=\beta \frac{\dot{\mathrm{L}}}{\mathrm{L}}+\alpha \frac{\dot{\mathrm{H}}_{\mathrm{Y}}}{\mathrm{H}_{\mathrm{Y}}}+\frac{\dot{\mathrm{A}}+\dot{\mathrm{A}}^{*}}{\mathrm{~A}+\mathrm{A}^{*}}-\mathrm{n} \\
& \frac{\dot{\mathrm{y}^{*}}}{\mathrm{y}^{*}}=\beta \frac{\dot{\mathrm{L}}^{*}}{\mathrm{~L}^{*}}+\alpha \frac{\dot{\mathrm{H}}_{\mathrm{Y}}^{*}}{\mathrm{H}_{\mathrm{Y}}^{*}}+\frac{\dot{\mathrm{A}}+\dot{\mathrm{A}}^{*}}{\mathrm{~A}+\mathrm{A}^{*}}-\mathrm{n}
\end{aligned}
$$

Portanto, as duas regiões se beneficiam da integração econômica, pois ambas obtêm maiores taxas de crescimento do que cada uma isoladamente. Verifica-se também que não ocorre a especialização setorial, ou seja, as duas regiões continuam engajadas na produção de novos projetos e de bens manufa- 
turados. Vale destacar que a análise do comportamento do consumo é idêntica à do caso anterior, alterando apenas a taxa de crescimento.

\subsection{Produtividade do Capital Humano Diferente entre as Regiôes $\left(\delta \neq \delta^{*}\right)$}

Caso a produtividade do capital humano das regiões seja diferente, mesmo com a difusão de conhecimento não ocorrerá a equalização salarial no setor de $P \& D$, haja vista que a região mais produtiva conseguirá produzir novos projetos a uma taxa superior à da outra região com o mesmo nível de conhecimento. Assim, o produto marginal do capital humano no setor de P\&D também será diferente, implicando salários também diferenciados.

Como resultado, a região mais produtiva atrairá a mão-de-obra qualificada da outra região para seu setor de P\&D, sendo que deverá ocorrer a especialização setorial. Além disso, a região mais produtiva deverá governar a trajetória de crescimento de ambas as regiões.

\section{CONCLUSÃO}

Em vista dos argumentos apresentados, e utilizando o instrumental de modelos de crescimento endógeno desenvolvido por Frenkel e Trauth (1998) e Rivera e Romer (1990), o presente trabalho, ao acrescentar taxas positivas de crescimento populacional, políticas de capacitação de capital humano e a possibilidade de ausência de difusão de conhecimento entre regiôes de um país, demonstrou que a integração econômica nacional tem efeitos positivos sobre as trajetórias de crescimento do produto per capita, do estoque de capital per capita e do consumo per capita das regióes integradas.

Constatou-se que na ausência de difusão de conhecimento e com igual produtividade do capital humano, desde que a região mais atrasada não qualifique mão-de-obra a uma taxa superior à da outra região, a economia com menor dotação inicial de conhecimento especializa-se completamente na produção de bens manufaturados, enquanto a região mais desenvolvida 
produz bens manufaturados e novas tecnologias. Nesta situação, verificase, igualmente, que o crescimento do produto per capita e do capital per capita de ambas as economias é governado pela economia com maior dotação inicial de capital humano.

Um resultado importante do trabalho é que se a economia com menor dotação inicial de conhecimento implementar um vigoroso processo de capacitação, que continuamente aumente sua força de trabalho qualificada a uma taxa superior à da outra região, e as diferenças na produtividade não forem significativas no momento da integração, o processo pelo qual esta se especializaria na produção de bens manufaturados é revertido, de modo que ela se torna mais competitiva no setor de P\&D que a outra região. Desta forma, sua economia fica diversificada em bens manufaturados e $\mathrm{P} \& \mathrm{D}$, enquanto a outra região especializa-se na produção de bens manufaturados. Além disso, o crescimento do produto e capital per capita de ambas economias é agora governado pela região anteriormente atrasada.

Sob a hipótese de difusão de conhecimento e idêntica produtividade, ambas as regiôes aumentam sua competitividade no setor de $\mathrm{P} \& \mathrm{D}$, sendo que não ocorre a especialização setorial em nenhuma das regióes, ou seja, ambas continuam produzindo bens manufaturados e novos projetos. Verifica-se também que o produto per capita, o capital per capita e o consumo per capita crescem a taxas maiores que em autarcia, uma vez que ambas as regiões tornaram-se mais produtivas e, conseqüentemente, competitivas em razão da difusão do conhecimento. Vale ressaltar que sob a hipótese de difusão de conhecimento, mesmo que uma das regiões qualifique mão-deobra a uma taxa superior à da outra região, os resultados não se alteram, já que qualquer ganho de produtividade, decorrente do emprego de mais capital humano, é plenamente compartilhado entre as regiões. Porém, caso a produtividade do capital humano seja diferente, mesmo com difusão de conhecimento, poderá ocorrer especialização setorial.

Em síntese, pelo exposto ao longo do trabalho, pode-se concluir que a integração nacional aumenta a taxa de crescimento das variáveis agregadas e também das variáveis per capita da economia, porém pode causar a especialização setorial. Isto ocorrerá caso a estrutura de produção das regiões 
sejam diferentes e não sejam adotados mecanismos que corrijam essas diferenças no período pós-integração.

\section{BIBLIOGRAFIA}

ABLAS, Luiz A. Q. et al. Dinâmica espacial do desenvolvimento brasileiro. São Paulo: IPE-USP, 1985.

AGHION, P.; HOWITT, P. Endogenous growth models. London-England: The MIT Press, 1988.

BALDWIN, Richard E.; FORSLID Rikard. The core-periphery model and endogenous growth: stabilising and de-stabilising integration. NBER Working Paper Series No 6899, 1999.

BARRO, Robert J.; SALA-I-MARTIN, Xavier. Economic growth. USA: Ed. McGraw-Hill, 1995.

FRENKEL, M.; TRAUTH, T. Time preference, productivity, and the growth effects of integration. 1998. Disponível no site http://ideas.uqam.ca em 10/12/1999.

FRIEDMAN, John. Planejamento regional: problema de integração espacial. In: Economia regional: textos escolhidos. Belo Horizonte: Cedeplar, 1977.

GIANNETTI, Mariassunta. The effects of integration on regional disparities: convergence, divergence or both? 1999. Disponível no site http:// www.ssrn.com em 15/06/2000.

JAFFE, Adam B.; TRAJTENBERG, Manuel. Flows of knowledge from universities and federal labs: modeling the flow of patents citations over time and across institutional and geographic boundaries. NBER Working Paper Series, No 5712, 1996.

KELLER, Wolfgang. How trade patterns and technology flows affect produtivity growth. NBER Working Paper Series, N 6990.

. Geographic localization of international technology diffusion. NBER Working Paper Series, No 7509, 2000.

KRUGMAN, P. The narrow moving band, the dutch disease, and the competitive consequence of Mrs. Thaecher. Journal of Developement Economics. 27, p. 41-45, 1987.

Increasing returns and economic geography. Journal of Political Economy, 99, p. 483-99, 1991. 
LAVINAS, L.; GARCIA, E.; AMARAL, M. R. Desigualdades regionais: indicadores socio-econômicos nos anos 90. Revista do Banco do Nordeste, 1996.

MAS-COLELL, Andreu et al. Microeconomic theory. New York: Oxford University Press, 1995.

RIVERA, Luis. A.; ROMER, Paul. M. Economic integration and endogenous growth. NBER Working Paper Series, $\mathrm{N}^{\circ} 3528$.

ROLIM, Cássio F C. Integração x integração: a busca dos conceitos perdidos. In: LAVINAS, Lena et al., Integração, região e regionalismo. Rio de Janeiro: Ed. Bertrand Brasil, 1994.

ROMER, David. Advanced macroeconomics. USA: Ed. McGraw-Hill, 1996.

ROMER, Paul M. Endogenous technological change. The Journal of Political Economy, v. 98, issue 5, p. S71-S102, 1990.

VARIAN, Hal R. Microeconomic analysis. $3^{\circ}$ ed. New York: Ed. W. W. Norton \& Company, 1992.

VERNABLES, A. Equilibrium location with vertically linked industries. Journal of International Economics, 1996.

Os autores agradecem aos pareceristas pelos comentários e sugestões. Quaisquer erros remanescentes são de inteira responsabilidade dos autores. Os autores agradecem também a CAPES pelo suporte financeiro.

(Recebido em abril de 2001. Aceito para publicação em abril de 2003). 